\title{
Quality improvement in cardiothoracic surgery residency: Training in the culture of change
}

Susan D. Moffatt-Bruce, MD, PhD, MBA, ${ }^{a}$ Madonna E. Lee, MD, ${ }^{b}$ and Peter J. Kneuertz, MD ${ }^{a}$

Feature Editor's Introduction-This article by MoffattBruce and colleagues showcases the importance of quality improvement (QI) projects in the medical field and how the cardiothoracic resident's training regimen makes them uniquely suited to tackle these QI endeavors. ${ }^{1}$ Due to the length of training and the pathologies of our patients, cardiothoracic surgeons are exposed to a sundry of clinical arenas and as a result, are able to identify areas in healthcare where patient safety and outcomes can be compromised.

Although the article's focus is on QI projects during training and how to integrate them into an already crammed curriculum, the reality is these QI projects will be part of the cardiothoracic surgeon's lifelong career. There will always be a need to do better for our patients. Preparations for the QI projects should start while in training with a formalized training plan and with dedicated mentors at the ready. Several tactics are described to achieve success including utilizing advanced practice providers to maximize clinical care, handing off long-term projects, using public fora to share knowledge, creating rewards systems to incite resident participation, and fostering faculty mentorship.

One particular point addressed in the article deserves to be emphasized: these QI projects are not just another checkbox to mark off from a long to-do list. These are important exercises that not only train us to identify failures in the health care system, but also as importantly, create an atmosphere for solutions. QI projects provide a powerful and impactful tool to shape the future of patient care-who better to wield it than cardiothoracic surgeons?

\section{Anh-Thu Le, MD, and Nahush A. Mokadam, MD}

The provision of high quality health care, in our everchanging environment, requires a remarkable combination of training, acquired skill, clinical judgment and teamwork.

\footnotetext{
From the a Division of Thoracic Surgery, Department of Surgery, The Ohio State University, Columbus, Ohio; and ${ }^{\mathrm{b}}$ Division of Congenital Cardiac Surgery, Department of Surgery, Seattle Children's Hospital, Seattle, Wash.

Received for publication Dec 5, 2019; revisions received March 3, 2020; accepted for publication March 7, 2020; available ahead of print June 9, 2020.

Address for reprints: Susan D. Moffatt-Bruce, MD, PhD, MBA, Department of Surgery, The Ohio State University Wexner Medical Center, 168 Doan Hall, 410 W 10th Ave, Columbus, OH 43210 (E-mail: Susan.moffatt-bruce@ osumc.edu).

J Thorac Cardiovasc Surg 2020;160:1255-60 0022-5223/ $\$ 36.00$

Copyright (c) 2020 Published by Elsevier Inc. on behalf of The American Association for Thoracic Surgery

https://doi.org/10.1016/j.jtcvs.2020.03.161
}

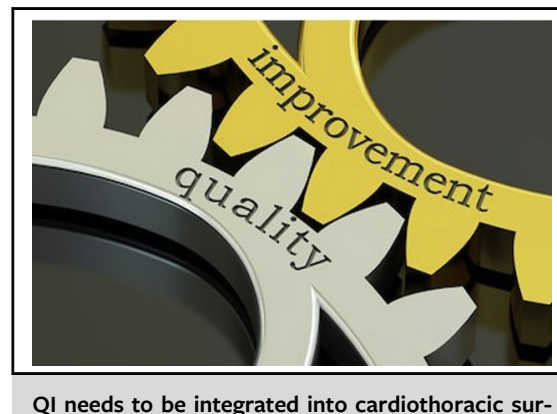
gery training as an essential element.

\section{CENTRAL MESSAGE \\ Quality improvement training is essential as we change to value- based care. Cardiothoracic sur- gery residents are perfectly adapted to engage and benefit from continuous learning.}

This Invited Expert Opinion provides a perspective on the following paper: J Am Coll Cardiol. 2019;74(20):2533-2537. https://doi.org/10.1016/j.jacc 2019.10 .004 .

See Commentaries on pages 1261 and 1262 .

Those that work within it are indeed privileged to be part of our profession of treating the ill, improving outcomes, and supporting patients and families. However, there are times when our care, despite our best intentions, does not result in the outcomes we had intended and may even cause harm. More than a decade ago, the Institute of Medicine released its famous report To Err Is Human, which set an ambitious goal for the world to reduce the number of patients harmed by medical errors and preventable adverse events. ${ }^{1}$ This resulted in the creation of an international agenda to improve the quality and safety of care provided for all patients. A number of new initiatives were launched, including electronic medical records, limiting resident work hours, and quality improvement training for physicians and trainees. ${ }^{2}$ This call to arms has ultimately helped in creating 
a culture of safety and accountability in our residency training programs that had not been previously formulized. ${ }^{2}$ The Accreditation Council for Graduate Medical Education (ACGME) embraced these initiatives and has worked to ensure that residents are indeed trained in quality improvement $(\mathrm{QI}){ }^{2}$ As such it is required that residency education occur in an environment that "emphasizes excellence in safety and quality of care" and further, "residents must demonstrate the ability to analyze the care they provide". ${ }^{2}$ Additionally, the ACGME requires that residents "work in a well-coordinated manner with other health care professionals to achieve organizational patient safety goals.". These important tenants of residency training are further supported by the ACGME requirements that residents are expected to have learning and the ability to make system-level changes so to ensure the best outcomes. ${ }^{2}$ Training our residents in QI is essential; it has been mandated and it is expected. But it is really hard work considering all that residents and faculty already have to do. It takes more than a checklist to achieve a safe environment for our patients and health care providers. Creating a culture of QI means ensuring that the highest quality of care is not just a project or flavor of the month but rather at the core of what we do every day, for every patient.

As part of the Next Accreditation System, the ACGME has provided a required program to ensure successful implementation and development of safety and quality of care at residency training institutions referred to as the Clinical Learning Environment Review (CLER) program. CLER focuses on 6 areas in teaching hospitals and the care residents would provide in a lifetime of practice after completion of training. ${ }^{3}$ The 6 areas encompass engagement of residents in patient safety, quality improvement and care transitions, promoting appropriate resident supervision, duty hour oversight and fatigue management, and enhancing professionalism. CLER surveyors visit clinical sites of sponsoring institutions with 2 or more specialty or subspecialty programs. The CLER site visits involve all departments, hospital leadership, nursing, and other support staff, emphasizing the multidisciplinary nature of the interactions of both trainees and patients and their influence on patient care. The feedback provided by the CLER program visits is designed to encourage clinical sites to actually improve and expect engagement of residents and fellows in learning to provide the highest quality of care and really endorse an environment of continuous quality improvement. ${ }^{3}$ This program has been essential to further emphasize the requirement for QI training in residencies.

Integrating QI into a formalized cardiothoracic surgery residency is therefore not only required, but also expected and continuously monitored at all levels of the organizations in which our residents train. We must be cognizant that there is a balance to not impose additional stress when trying to balance quality initiatives, meeting patient expectations, and competency-based training needs. Trainees have many requirements, including obtaining surgical skills, knowledge, clinical competencies, and research. So how do we balance an already demanding schedule with what could be perceived as another checkbox? There are some adaptations to residency training programs that have already occurred in the clinical setting due to restrictions to resident work hours. There are roles within QI such as data gathering or data analysis that can be performed by nonphysicians. Similarly, increasing engagement of advanced practice providers in care and actual QI projects has the potential to decrease the less-educational clinical burden on residents, allowing residents more time to sponsor QI initiatives. Subsequently, clinical nonresident staff can become valuable resources when building a multidisciplinary team to collaborate with resident-led QI initiatives. Ongoing hospital-led QI initiatives welcome resident involvement and can provide resourcing. Focusing specifically on QI residency training, through thoughtfully incorporating QI skill training into a curriculum and integrating this learning with faculty mentorship, residents can gain guidance and support so to ultimately benefit themselves, their training institutions, and the patients they care for.

\section{CARDIOTHORACIC SURGERY RESIDENTS ARE UNIQUELY EQUIPPED FOR QI INITIATIVES}

Cardiothoracic surgery, due to its complexity both relative to the operations and the associated physiologic effects, in addition to its dependence on multiple team members, has inherent clinical challenges and therefore a real need for continuous QI. Furthermore, the nature of cardiothoracic surgery, as well as the rigors and experiences in surgical training, provide our residents a unique perspective and possibilities to make a difference through QI. During their training, cardiothoracic surgery residents work in various roles in our complex medical systems with increasing autonomy and graduated responsibility as they peak in their surgical training. Residents often work at multiple institutions, quickly acquiring practical skills necessary to provide clinical care in the various settings. These rotations frequently change every few months, requiring successful residents to become adaptable to constantly changing health care environments. Cardiothoracic surgical residents interact with numerous different specialties and disciplines every single day. Across these different venues and clinical situations, residents work as the frontline and witnessed medical errors 
and inefficiencies and the real opportunities for improvement. Having such a range of clinical exposure make them primed to improve care delivery pathways, collaborate, and offer perspectives for improvement. As such, residents who are connected within their medical system and understand its strengths and weaknesses are particularly aware of system issues, and have are effective collaborators in system-based QI initiatives. ${ }^{4,5}$ A teambased approach comes natural to the current generation of residents, and perhaps is more amplified in surgical specialties such as cardiothoracic surgery, that requires highly functional teams to work effectively. ${ }^{6}$ Surgical residents are therefore well positioned to address problems that they face on a daily basis, with firsthand knowledge of challenges they encounter and to find solutions that will optimize patient safety often through improved team communication.

The length and acuity of surgical training is certainly amenable to empowering resident-led QI initiatives. To obtain cardiothoracic surgical specialty fellowship positions, surgical trainees must complete a general surgery residency (range, 5-8 years). So, although cardiothoracic fellowships are shorter (2-3 years), these advanced surgical trainees start with at least half a decade of experience, and already some resident QI experience in most cases. Even integrated cardiothoracic residency programs, which incorporate general surgery rotations, are an average of 6 years. This is longer than the average medical residency. Thus, surgical residents tend to have developed clinical longevity, enhanced competency in navigating complex health care systems, and often integrated their personalized visions for QI as they grow in their leadership skills. They begin to recognize that achieving excellent surgical outcomes does not occur in isolation to the operating room and that surgical outcomes are often measured by at least their institution. The different phases of surgical care also afford even more opportunities for cardiothoracic surgery residents' clinical areas of influence to include preoperative, intraoperative and postoperative care, and how they are interrelated. Training at 1 institution for many years allows the potential for successfully completing a QI project.

Although QI projects can take a prolonged period, sustainability may be achieved through passing the torch from graduating residents to junior trainees. In the relatively short cardiothoracic fellowships, incoming trainees can engage in projects from previous trainees who have graduated through a hand-off process, remote communication, and faculty involvement. This relayrace concept allows for the continuation of complex projects, completion of larger QI endeavors, and eventual sustainability.

\section{HOW DO CARDIOTHORACIC SURGERY RESIDENTS BENEFIT FROM BEING INVOLVED IN QI?}

Surgical safety and quality initiatives are a priority for many hospitals, large and small, across the nation. ${ }^{7}$ Through thoughtful investment in resident QI training and initiatives, health care entities can enable both the individual trainees as well as residents as a whole by empowering them to fix problems endemic to our medical systems. Most surgical residents are interested in their specialty due to factors that align well with QI initiatives, including career satisfaction in realizing immediate patient benefits, problem-solving, and team building. In a training program without QI imbedded, there will be rare opportunity for residents to utilize their ambition to solve problems and really be part of the solution. Residents who identify their own QI projects will find it more relevant and will ultimately lead to more motivation and participation, and ultimately sustainable results. ${ }^{8}$ QI initiatives can also directly benefit residents by focusing specifically on improving resident education initiative. Residents can apply QI in identifying areas they believe are lacking in their own curriculum which can result in initiatives include hardwiring simulation labs into their training, which ultimately improve patient outcomes. ${ }^{9}$ Resident QI initiatives can also be easily incorporated into already established hospitalwide QI initiatives, such as infection prevention, because residents have so much contact with patients on a daily basis. Residents are truly the front line. Even if their projects are unsuccessful by traditional quality metrics, learning about the process and the inner workings of health care institutions can be extremely valuable. Lastly, QI projects foster important relationships and teamwork between trainees, as residents of different years are involved in the same project and allow for mentoring between senior to junior residents.

\section{QUALITY TRAINING AS A ROAD TO SUCCESS}

Training in QI is a valuable investment for the future of cardiothoracic trainees on several levels. A formal education in quality methods may equip trainees with tools to influence their own surgical outcomes and set the stage for lifelong learning. It will also create attractive career opportunities. There are a multitude of formal educational resources available for quality-oriented surgeons. Some are more intensive than others and can be tailored to what is required based on need and interest of the trainee (Table 1). An example of a successful formalized curriculum for surgical residents was published by Mrdutt and colleagues, ${ }^{10}$ whereby a 2-year QI curriculum, using the American College of Surgeons National Surgical Quality Improvement Program database to address common 
TABLE 1. Resident quality improvement training opportunities

\begin{tabular}{lcc}
\hline \multicolumn{1}{c}{ Program } & Details & Link \\
\hline American College of Surgeons & Quality in training curriculum & https://qiti.acsnsqip.org/ACS_NSQIP_2017 \\
American Society for Quality (ASQ) & ASQ delivers Lean Sigma training using D- & http://asq.org/healthcare-use/training/ \\
Learning Institute & M-A-I-C methodology with integrated & overviewtml \\
& Lean tools and techniques & http://www.baylorhealth.edu/ \\
STEEEP Academy & The STEEEP Academy teaches health care & STEEEPGlobalInstitute/ \\
(safety, timeliness, efficacy, efficiency, & leaders the theory and techniques of rapid- & STEEEPAcademy/Pages/default.aspx \\
equity, and patient-centeredness) & cycle quality improvement & http://www.ncqa.org/EducationEvents.aspx \\
National Committee for Quality Assurance & NCQA offers a host of live educational & \\
(NCQA) & seminars and just-in-time webinars & http://www.ihi.org/education/Pages/default. \\
Institute for Healthcare Improvement (IHI) & Conferences, in-person training, Web-based & aspx \\
& training, audio and video programs, IHI & http://www.ihi.org/education/ \\
& Open School, IHI Fellowship Program & IHIOpenSchool/Pages/default.aspx \\
http://ece.emory.edu/sixsigma/ & http://www.hrsa.gov/publichealth/ \\
guidelines/qualityimprovement.html
\end{tabular}

US Department of Health and Human

Services

\begin{tabular}{|c|c|c|}
\hline $\begin{array}{l}\text { TeamSTEPPS } \\
\text { Agency for Healthcare Research and Quality }\end{array}$ & $\begin{array}{l}\text { TeamSTEPPS is a teamwork system designed } \\
\text { for health care professionals }\end{array}$ & http://teamstepps.ahrq.gov/ \\
\hline World Health Organization (WHO) & $\begin{array}{l}\text { WHO Patient Safety has developed a range of } \\
\text { training materials and tools }\end{array}$ & $\begin{array}{l}\text { http://www.who.int/patientsafety/education/ } \\
\text { en/ }\end{array}$ \\
\hline $\begin{array}{l}\text { US Cochrane Center } \\
\text { Understanding Evidence-Based Healthcare }\end{array}$ & $\begin{array}{l}\text { Web course created by the United States } \\
\text { Cochrane Center as part of a project } \\
\text { undertaken by Consumers United for } \\
\text { Evidence-based Healthcare }\end{array}$ & $\begin{array}{l}\text { http://us.cochrane.org/understanding- } \\
\text { evidence-based-healthcare-foundation- } \\
\text { action }\end{array}$ \\
\hline $\begin{array}{l}\text { Johns Hopkins Medicine } \\
\text { Armstrong Institute for Patient Safety and } \\
\text { Quality }\end{array}$ & $\begin{array}{l}\text { Workshops and e-Learning: } \\
\text { The Armstrong Institute hosts training } \\
\text { workshops throughout the year targeted to } \\
\text { a wide range of health care professionals, } \\
\text { from frontline staff to executives }\end{array}$ & $\begin{array}{l}\text { http://www.hopkinsmedicine.org/armstrong_ } \\
\text { institute/training_services/workshops. } \\
\text { html }\end{array}$ \\
\hline Intermountain Healthcare & $\begin{array}{l}\text { The Advanced Training Program offers a } \\
\text { course for health care professionals who } \\
\text { need to teach, implement, and investigate } \\
\text { quality improvement }\end{array}$ & $\begin{array}{l}\text { http://intermountainhealthcare.org/ } \\
\text { qualityandresearch/institute/courses/atp/ } \\
\text { Pages/home.aspx }\end{array}$ \\
\hline Duke University & $\begin{array}{l}\text { Patient Safety - Quality Improvement } \\
\text { Evidence-based medicine workshop }\end{array}$ & $\begin{array}{l}\text { http://patientsafetyed.duhs.duke.edu/ } \\
\text { http://sites.duke.edu/ebmworkshop/ }\end{array}$ \\
\hline $\begin{array}{l}\text { Six Sigma Green Belt Healthcare } \\
\text { University of Michigan }\end{array}$ & $\begin{array}{l}\text { Focuses on Six Sigma Green Belt training on } \\
\text { health care applications }\end{array}$ & $\begin{array}{l}\text { http://cpd.engin.umich.edu/professional- } \\
\text { programs/six-sigma-greenbelt-healthcare/ } \\
\text { index.htm }\end{array}$ \\
\hline $\begin{array}{l}\text { Masters of Operational Excellence } \\
\text { Fisher College of Business, The Ohio State } \\
\text { University }\end{array}$ & $\begin{array}{l}\text { An } 18 \text {-mo degree focusing on developing } \\
\text { leaders; leadership in the emerging, rapid, } \\
\text { and continuous improvement environment } \\
\text { found in leading service, health care, and } \\
\text { manufacturing organizations }\end{array}$ & http://fisher.osu.edu/mboe/ \\
\hline
\end{tabular}

postoperative complications, was created. Surgical residents were able to assess how their institution compared with national outcomes, and create interventions to improve their rankings. Their experience demonstrated the potential to not only improve resident knowledge, but also to positively affect clinical performance and local culture. Other benefits of completing QI curricula include development of leadership skills, coaching, building 
interprofessional relationships, and engaging with nonclinical hospital QI personnel, such as data specialists who help to augment the resident experience. ${ }^{11-13}$ These skills can translate into QI roles in the future and can be helpful in becoming a medical director of quality, chief quality officer or chief medical officer. Resident postcurriculum questionnaires have demonstrated that residents participating in a formalized QI group are more knowledgeable about methodology, better prepared for implementing their own project, and more likely to participate in QI in the future when they themselves become faculty. ${ }^{14}$

\section{HIGH-YIELD QI PROJECTS}

The potential success of a QI project depends on the relationship between the significance of the outcome it may influence and the effort required to make change. In our experience, the most successful projects are often the low hanging fruit or very practical changes no one has previously thought to influence. The ideal project addresses a clear and confined problem, and has an end point that is relevant and measurable. Such projects may involve process improvements such as algorithms for common or high-risk clinical situation, or affecting behavior changes through addressing knowledge gaps or targeted interventions. A perfect example would be compliance with handwashing. Residents are competitive and compliance is measured. Setting up small competitions, often involving food as rewards, can make a huge difference. These improvements, which residents are very able to influence, can build on the existing strengths within an organization but must be supported by available data and active engagement of key stakeholders. These successful, high-yield QI projects should encourage residents to actively work with team members to allow them to consider institutional culture and make changes that are required to ensure sustainable change.

\section{ENABLERS OF QI TRAINING}

Faculty mentorship and encouragement is essential and instrumental in shaping the QI experience of our residents. QI opportunities can be created when faculty direct residents to resources within the hospital, and incorporate QI activities into aspects of the education program such as their core competencies and regularly scheduled events such as grand rounds. Encouraging residents to encounter their difficulties and learn from mistakes, such as during constructive and safe morbidity and mortality conferences, is a good start and will ultimately set the tone for a thriving QI culture. ${ }^{15,16}$ Practically, some initiatives need faculty supervision and oversight to be considered valid within the hospital setting at an institutional level. Simultaneous education for faculty, who may have a gap in QI knowledge and experience, can promote shared accountability of patient outcomes and should be part of ongoing faculty development and patient safety cultural reform. ${ }^{17}$ Well-equipped mentors and faculty who are supportive and impart QI experiences to the next generation of residents and physicians is increasingly recognized as fundamental to any academic institution focused on quality as a mission. ${ }^{18}$

From a higher level, hospitals and health systems may enable QI resident education by providing a supportive infrastructure and encouraging public forums. A successful example at our institution was the Inaugural Resident \& Fellow Quality Improvement Symposium during Fall 2018. The event was sponsored by the graduate medical education office, with support from the health system quality and patient safety office. During this event, trainees from multiple specialties had opportunities to showcase their projects. Scholarships were made available for resident projects, including most collaborative, an audience award chosen by the audience members via real-time voting, and a grand prize to attend a national conference. The event, which has since been repeated, was resident initiated. Most importantly, it was attended by patients and their families who support QI initiatives to ensure outcomes matter. All 20 projects were creative, collaborative, and included faculty mentorship. Surgical residents focused on measuring and decreasing frequency of foot-traffic during operating room times in an attempt to decrease surgical site infections, and decreasing postoperative opioid-use by implementing a daily rounding checklist. Other projects included decreasing implantation of permanent pacemakers after transcatheter aortic valve implantation by instituting a postimplantation screening protocol and prolonged monitoring, and decreasing chest-tube insertion complications in the emergency department through resident education initiatives.

QI plays a required and integral role in cardiothoracic surgical training. Residents have a unique perspective into the complexities of cardiothoracic clinical care on the front line. The QI experience for trainees may be both engaging and rewarding. In addition to the influence on patient care, there are many other benefits of QI work for cardiothoracic trainees, including educational and personal value, fulfillment of training requirements, scholarship, and future career opportunities. Keys for successful QI initiatives for trainees include dedicated and educated faculty mentorship, alignment with hospital or health system goals, and the selection of projects with clear and achievable goals. Formalized QI training within cardiothoracic surgery residencies, with aligned institutional and faculty support, is the change we need to not only ensure better outcomes for our patients, but also to ensure residency training that is contemporary and responsive to change.

\section{Conflict of Interest Statement}

The authors reported no conflicts of interest. 
The Journal policy requires editors and reviewers to disclose conflicts of interest and to decline handling or reviewing manuscripts for which they may have a conflict of interest. The editors and reviewers of this article have no conflicts of interest.

\section{References}

1. Institute of Medicine. Crossing the quality chasm. Washington, DC: National Academies Press; 2003.

2. Accreditation Council for Graduate Medical Education. ACGME common program requirements (residency). Available at: https://www.acgme.org/Portals/0/ PFAssets/ProgramRequirements/CPRResidency2019.pdf. Accessed November 30, 2019.

3. Accreditation Council for Graduate Medical Education. CLER Pathways to Excellence Expectations for an optimal clinical learning environment to achieve safe and high quality patient care. Available at: https://www.acgme.org/Portals/0/ PDFs/CLER/CLER Brochure.pdf. Accessed November 30, 2019.

4. Siri J, Reed AI, Flynn TC, Silver M, Behrns KE. A multidisciplinary systemsbased practice learning experience and its impact on surgical residency education. J Surg Educ. 2007;64:328-32.

5. Gillen JR, Ramirez AG, Farineau DW, Hoke TR, Schirmer BD, Williams MD, et al. Using interdisciplinary workgroups to educate surgery residents in systems-based practice. J Surg Educ. 2016;73:1052-9.

6. Barmparas G, Imai TA, Gewertz BL. The millennials are here and they expect more from their surgical educators! Ann Surg. 2019;270:962-3.

7. Ingraham AM, Richards KE, Hall BL, Ko CY. Quality improvement in surgery: the American College of Surgeons national surgical quality improvement program approach. Adv Surg. 2010;44:251-67.
8. Kelz RR, Sellers MM, Merkow R, Aggarwal R, Ko CY. Defining the content for a quality and safety in surgery curriculum using a nominal group technique. J Surg Educ. 2019;76:795-801.

9. Starr M, Sawyer T, Jones M, Batra M, McPhillips H. A simulation-based quality improvement approach to improve pediatric resident competency with required procedures. Cureus. 2017;9:e1307.

10. Mrdutt MM, Isbell CL, Regner JL, Hodges BR, Munoz-Maldonado Y, Thomas JS, et al. NSQIP-based quality improvement curriculum for surgical residents. J Am Coll Surg. 2017;224:868-74.

11. Sellers MM, Fordham M, Miller CW, Ko CY, Kelz RR. The quality in-training initiative: giving residents data to learn clinical effectiveness. J Surg Educ. 2018;75:397-402.

12. Sellers MM, Reinke CE, Kreider S, Meise C, Nelis K, Volpe A, et al. American College of Surgeons NSQIP: quality in-training initiative pilot study. J Am Coll Surg. 2013:217:827-32.

13. Starr SR, Kautz JM, Sorita A, Thompson KM, Reed DA, Porter BL, et al. Quality improvement education for health professionals: a systematic review. Am J Med Qual. 2016;31:209-16.

14. Duello K, Louh I, Greig H, Dawson N. Residents' knowledge of quality improvement: the impact of using a group project curriculum. Postgrad Med J. 2015;91: 431-5.

15. Abelson JS, Mitchell KB, Afaneh C, Rich BS, Frey TJ, Gellman C, et al. Quality improvement-focused departmental grand rounds reports: a strategy to engage general surgery residents. J Grad Med Educ. 2016;8:232-6.

16. Smith SR, Bakshi R. Promoting resident involvement in quality improvement initiatives through faculty involvement and curriculum. J Grad Med Educ. 2015;7: 119-20.

17. Kelz RR, Sellers MM. Invited commentary: education as a pathway to sustainable improvement. J Am Coll Surg. 2017;224:874-5.

18. Wong BM, Levinson W, Shojania KG. Quality improvement in medical education: current state and future directions. Med Educ. 2012;46:107-19. 